\title{
AVALIAÇÃO AGRONÔMICA DE UM BIOSSÓLIDO NA PRODUTIVIDADE DA COUVE
}

\author{
Saidelamine Mahadal ${ }^{1}$, Malaquias Tsambe ${ }^{1}$, Armindo Monjane ${ }^{2}$, Gino Roberto Gehling ${ }^{3 *}$ \\ ${ }^{1}$ Doutorando, UFRGS - IPH, 91501-970, Porto Alegre, Brasil. \\ 2 Professor Associado, UP - FCNM, CEP, Maputo, Moçambique. \\ 3 Professor Associado, UFRGS - IPH, 91501-970, Porto Alegre, Brasil.
}

*E-mail: grgehling@gmail.com

\section{RESUMO}

O presente trabalho avalia a viabilidade agronômica de um biossólido, resultante da mistura de lodo da estação de tratamento de esgotos (ETE) da indústria de refrigerantes, palha de soja e terra para a cultura de couve Brassica oleleracea da variedade tronchuda. O ensaio de campo foi realizado em um solo caracteristicamente pedalférico, destacando-se os solos vermelhos argiloarenosos, diferenciados na base da textura média ou argilosa, de camada superficial castanho-avermelhada no período de fevereiro a junho de 2012. O biossólido produzido apresentou uma relação nutricional de 0,5:1,0:0,2. O campo de ensaio foi dividido em nove parcelas. Três delas foram tratadas com o biossólido, três com adubo mineral e as três restantes foram definidas como parcelas de controle. Nas parcelas tratadas com biossólido foram adicionadas 30 gramas dele em cada pé de couve. A produtividade relativa foi definida tendo em conta os parâmetros: altura da planta, comprimento da folha, largura da folha e peso da folha. O biossólido melhorou a fertilidade do solo, o estado nutricional e a produtividade da couve superando a parcela de controle em cerca de 40,3\%. Porém, teve uma eficiência relativamente menor que a parcela de adubação mineral, na ordem de $48,7 \%$, podendo se considerar que o biossólido teve um rendimento mais próximo ao de adubação mineral. Os resultados mostram que o biossólido produzido a partir do lodo da estação de tratamento de esgotos da indústria de refrigerantes incrementa a produtividade do solo.

Palavras-chave: Lodo de ETE, biossólido, fertilidade do solo, couve Brassica oleleracea.

\section{Introdução}

A compostagem é definida como uma bioxidação aeróbia exotérmica de um substrato orgânico heterogêneo, caracterizado pela produção de dióxido de carbono, água, substâncias minerais e formação de matéria orgânica estável [1]. Dentre os vários substratos usados para a compostagem, pode-se destacar o lodo de esgoto em razão do elevado teor de matéria orgânica em sua composição, que pode representar mais de 50\% de sua matéria seca, dependendo do sistema de tratamento de esgoto utilizado [2]. Outros importantes constituintes do lodo são hidrocarbonetos, aminoácidos, proteínas ou lípidos, proporções de nitrogênio e fósforo, tendo em conta o tipo de esgoto gerado [1]. O lodo de esgoto é um subproduto resultante de tratamento de águas residuais, mas pode ser utilizado na forma de composto, para correção de solo, em função do seu teor de nutrientes e matéria orgânica, melhorando a fertilidade e propriedades físicas dos solos e aumentando a produtividade agrícola $[3,4]$.

A aplicação agrícola fornece uma alternativa de baixo custo para a disposição do lodo, mas é essencial que ele seja estabilizado antes da sua aplicação para minimizar potenciais problemas ambientais, tais como: patógenos, metais pesados e compostos orgânicos indesejáveis [5]. A adição de matéria orgânica ao solo proporciona inúmeros benefícios, como o aumento da capacidade de troca de cátions, aumento da capacidade de retenção de água, além de disponibilizar nutrientes às plantas. Dessa forma, considerando que o lodo de esgoto pode ser uma fonte de matéria orgânica e de nutrientes, o uso agrícola do composto à base desse resíduo tornou-se uma alternativa para o destino de grande quantidade de material gerado nas ETE Estações de Tratamento de Esgotos [6].

Diversos estudos com diferentes culturas têm demonstrado que as melhorias físicas e químicas do solo proporcionadas pelo uso de composto a base de lodo de esgoto aumentaram a fertilidade dos solos, resultando em aumento na produtividade de diversas culturas agrícolas avaliadas [7]. Outros autores [8] estudaram diferentes doses de composto à base de lodo de esgoto na fertilização da pupunheira, em neosolo fúlvico, e obtiveram aumento linear da produtividade como resultado do aumento das doses aplicadas do composto. Em área cultivada 
com milho, observou-se aumento na produção de grãos nos tratamentos com uso do resíduo orgânico [9]. Estudos de fertilização realizados em cana-de-açúcar com doses de composto à base de lodo de esgoto, combinadas ou não com fertilizantes nitrogenados e fosfatados, permitiram observar que nos tratamentos com o composto, combinados ou não com fertilizantes, mostraram aumento do número de colmos produzidos [10].

Nesta perspectiva, o presente estudo tem como finalidade avaliar a relação quantitativa entre a matéria orgânica do composto produzido à base de lodo de esgoto e palha de soja em relação ao crescimento da couve Brassica oleleracea, no que diz respeito aos parâmetros altura da planta, comprimento, largura e peso das folhas.

\section{Parte Experimental}

\subsection{Localização da área de estudo}

$\mathrm{O}$ estudo foi realizado na cidade de Lichinga, na região norte de Moçambique (Figura 1), no período de fevereiro a junho de 2012. A região é caraterizada por um clima tropical úmido, apresentando uma umidade média relativa de $74,5 \%$. A temperatura média no período de estudo foi de $18,6{ }^{\circ} \mathrm{C}$ e precipitação média de $109 \mathrm{~mm}$, sendo o período chuvoso entre novembro a abril [11].

Os solos predominantes em Lichinga são do tipo pedalféricos, destacando-se os solos castanho-avermelhados argiloarenosos, diferenciados na base da textura média ou argilosa, de camada superficial castanho-avermelhada, com profundidade moderada e $\mathrm{pH}$ ligeiramente ácidos [12].
Apesar de possuírem estrutura física adequada para a agricultura, os solos têm sua fertilidade natural diminuída pela prática de queimadas para limpá-los, não se prestando assim ao cultivo por períodos muito longos. Esta é uma das causas principais da agricultura itinerante, que incorpora novas terras ao plantio por meio de desmatamento e queimadas [13].

A vegetação natural é característica da África austral e central, considerada floresta miombo, dominada pelas espécies Brachystegia e Julbernardia.

\subsection{Composição química do solo da estação experimental}

As análises de solo (Tabela 1) foram feitas pelo laboratório da EMBRAPA Trigo, localizado no município de Passo Fundo, Rio Grande de Sul, Brasil. A amostra foi recolhida a uma profundidade de $20 \mathrm{~cm}$ (amostra composta) e os ensaios foram realizados de acordo com as normas de adubação e calagem para os estados de Rio Grande do Sul e de Santa Catarina.

O solo da estação experimental é moderadamente ácido, pois seu $\mathrm{pH}$ é menor que 6,5, típico de regiões úmidas (argiloarenosos). Por sua vez, a argila da estação experimental tem alta atividade de troca catiônica, pois, quando o solo apresenta capacidade de troca catiônica (CTC) e capacidade de troca catiônica efetiva (CTCe) maior que $24 \mathrm{mmol}_{\mathrm{c}} / \mathrm{dm}^{3}$, é considerado altamente ativo [1]. Essa atividade influencia a retenção de água dos solos e de nutrientes para as plantas e é, em parte, responsável pela coesão e adesão das partículas que garantem a consistência do solo. Em solos com alta atividade há movimentos de contração, quando secos, e de expansão quando

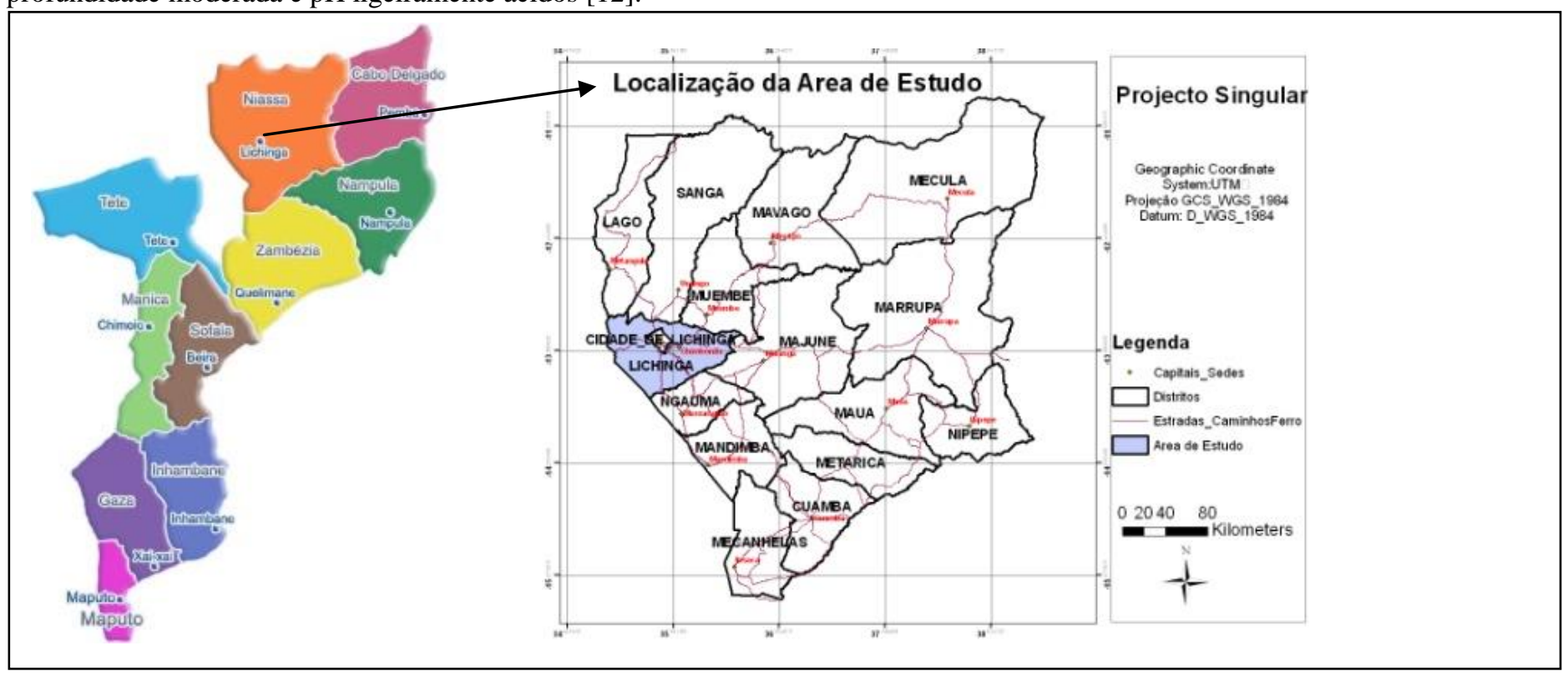

Figura 1- Localização da área de estudo (fonte: www.niassa.gov.mz, 2012). 


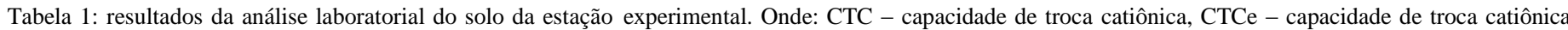
efetiva, $\mathrm{CE}$ - condutividade elétrica, $\mathrm{MO}$ - matéria orgânica, $\mathrm{N}_{\text {total }}-$ Nitrogênio total

\begin{tabular}{|c|c|c|c|c|c|c|c|c|c|c|}
\hline Parâmetro & $\begin{array}{c}\text { Argila } \\
\left(\mathrm{g} / \mathbf{d m}^{3}\right)\end{array}$ & $\begin{array}{c}\text { pH } \\
\text { em água }\end{array}$ & $\begin{array}{c}\text { pH } \\
\text { SMP }\end{array}$ & $\begin{array}{c}\mathbf{P} \\
\left(\mathrm{mg} / \mathrm{dm}^{3}\right)\end{array}$ & $\begin{array}{c}\mathrm{K} \\
\left(\mathrm{mg} / \mathrm{dm}^{3}\right)\end{array}$ & $\begin{array}{c}\mathrm{MO} \\
\left(\mathrm{g} / \mathrm{dm}^{3}\right)\end{array}$ & $\begin{array}{c}\mathrm{Al} \\
\left(\mathrm{mmol}_{\mathrm{c}} / \mathbf{d m}^{3}\right)\end{array}$ & $\begin{array}{c}\mathrm{Ca} \\
\left(\mathrm{mmol}_{\mathrm{c}} / \mathrm{dm}^{3}\right)\end{array}$ & $\begin{array}{c}\mathrm{Mg} \\
\left(\mathrm{mmol}_{\mathrm{c}} / \mathrm{dm}^{3}\right)\end{array}$ & $\begin{array}{c}\mathbf{H}^{+} / \mathbf{A l} \\
\left(\mathbf{m m o l}_{\mathrm{c}} / \mathbf{d m}^{3}\right)\end{array}$ \\
\hline Valor & 440,0 & 5,1 & 5,8 & 23,7 & 116,0 & 24,0 & 6,5 & 11,5 & 4,5 & 54,9 \\
\hline Parâmetro & $\begin{array}{c}\mathrm{CTC} \\
\left(\mathrm{mmol}_{\mathrm{c}} / \mathbf{d m}^{3}\right)\end{array}$ & $\begin{array}{c}\mathrm{CTC} \\
\left(\mathrm{mmol}_{\mathrm{c}} / \mathbf{d m}^{3}\right)\end{array}$ & $\begin{array}{c}\text { CTCe } \\
\left(\mathrm{mmol}_{\mathrm{c}} / \mathrm{dm}^{3}\right)\end{array}$ & $\begin{array}{c}\mathrm{S} \\
\left(\mathrm{mmol}_{\mathrm{c}} / \mathrm{dm}^{3}\right)\end{array}$ & $\begin{array}{c}\text { Al } \\
(\%)\end{array}$ & $\begin{array}{c}\mathbf{C} \mathbf{a}_{\text {saturação }} \\
(\%)\end{array}$ & $\begin{array}{c}\text { Mg } \\
(\%)\end{array}$ & $\begin{array}{c}\mathbf{K}_{\text {saturação }} \\
(\%)\end{array}$ & $\begin{array}{c}\mathbf{H}^{+} / \mathbf{A l}_{\text {saturação }} \\
(\%)\end{array}$ & \\
\hline Valor & 73,8 & 73,8 & 25,5 & 19,0 & 25,5 & 15,6 & 6,1 & 4,0 & 74,3 & \\
\hline
\end{tabular}

úmidos, mesmo tendo em conta o tipo de argila predominante (esmectita, vermiculita e montmorilonita), podendo ainda ocorrer formação de fendas e superfícies de compressão, quando secos, e microrrelevos, quando úmidos.

\subsection{Produção de composto (biossólido)}

O composto foi produzido a partir da mistura de lodo de ETE, palha de soja e terra vermelha, na proporção de 1:0,5:1, em um processo controlado em um biodigestor. O processo de compostagem, representado na Figura 2, visava garantir que os compostos orgânicos biodegradáveis passem por sucessivas etapas de transformação sob a ação de diversos grupos de microorganismos, resultando em um processo bioquímico complexo.

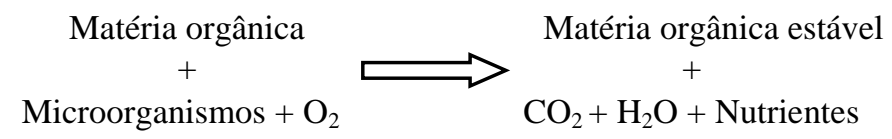

Figura 2: Esquema simplificado do processo de compostagem, adaptado de [1].

O lodo utilizado para a produção do biossólido é derivado de indústria de refrigerantes, obtido no leito de secagem da ETE da empresa, e é classificado como sendo um resíduo de classe II - resíduo não inerte [14].

Os fatores controlados durante a formação do composto foram: aeração, umidade e temperatura, não tendo se quantificado os nutrientes.

O processo de produção de composto contemplou a mistura de palha de soja e terra pelo fato do lodo da ETE apresentar granulometria fina e, quando parcialmente desidratado, apresentava aspecto pastoso, o que dificulta a difusão de ar. Nesse sentido, a incorporação da terra e palha de soja visava garantir a estrutura da mistura permitindo a criação de espaços vazios para garantir a difusão do ar [1].

\subsection{Análises laboratoriais do composto (biossólido)}

As análises laboratoriais foram realizadas no laboratório de solos do Instituto de Investigação Agronômica de Moçambique (IIAM). Os parâmetros analisados foram [12]:

- Determinação da quantidade de fósforo assimilável pelo método de Olsen, que consiste na extração da amostra com o $\mathrm{NaHCO}_{3}$ à $\mathrm{pH} 8,5$. Os fosfatos são extraídos na forma de um complexo azul de fósforo-molibdênio, o qual é determinado espectofotometricamente a $882 \mathrm{~nm}$.
- Determinação do $\mathrm{pH}-\mathrm{H}_{2} \mathrm{O}$ e $\mathrm{pH}-\mathrm{KCl}$ no solo pelo método de suspensão em água que consiste na determinação de $\mathrm{pH}$ potenciometricamente na suspensão de solo/água $(1: 2,5)$ e na suspensão de solo/cloreto de potássio $1 \mathrm{~N}(1: 2,5)$.

- Determinação do carbono orgânico, por meio do método de calcinação que consiste na queima da mistura na mufla até $500{ }^{\circ} \mathrm{C}$, seguida de pesagem para determinar a diferença de massa entre a parcela orgânica e mineral.

- Determinação do nitrogênio total pelo método de Kjeldahl que consiste em transformar o nitrogênio do solo em íon amônio $\left(\mathrm{NH}_{4}{ }^{+}\right)$, pela oxidação do mesmo com ácido sulfúrico concentrado, utilizando sulfato de potássio na presença de selênio e sulfato de cobre como catalizador. Depois da digestão, o amônio é destilado na presença de um álcali e a amônia $\left(\mathrm{NH}_{3}\right)$ é recolhida em uma solução de ácido bórico e titulada com ácido clorídrico.

- Determinação das bases trocáveis $\left(\mathrm{Ca}^{2+}, \mathrm{Mg}^{2+}, \mathrm{Na}^{+}\right.$, $\mathrm{K}^{+}$), consistiu na agitação do biossólido com acetato de amônio $1 \mathrm{~N}$ ( $\mathrm{pH} 7$ ). No extrato, o cálcio e o magnésio são determinados por complexometria e titulados com EDTA, enquanto o potássio e o sódio são determinados no fotômetro de chama.

- Determinação da textura pelo método de pipeta Robinson, que consiste em fazer o pré- tratamento do solo com $\mathrm{HCl}$ e $\mathrm{H}_{2} \mathrm{O}_{2}$ para eliminar o material que contribui para formação e manutenção dos agregados de partículas.

\subsection{Ensaios com a cultura de couve (Brassica oleracea)}

A cultura de couve foi preparada lançando-se a semente no viveiro, com germinações ao quinto dia. Em seguida, colocaram-se as mudas de couve no campo definitivo.

O campo definitivo era uma área de $100 \mathrm{~m}^{2}$, caracterizada por ser de fertilidade média, que foi dividida em nove parcelas, as quais, posteriormente, foram identificadas de forma aleatória (Figura 3). Nessa área foram definidos três tratamentos, distribuídos em três blocos aleatórios, totalizando nove parcelas de $9 \mathrm{~m}^{2}$ cada, com três linhas de $3 \mathrm{~m}$ de comprimento, com espaçamentos de $0,5 \mathrm{~m}$ e com 20 plantas por cada parcela. Em cada tratamento havia 20 plantas, ou seja, em cada repetição havia 60 plantas, conferindo um total de 180 plantas em todo ensaio.

As parcelas de ensaio foram tratadas com composto (biossólido) e com adubo NPK. A preparação dos solos consistiu no revolvimento, nivelamento e alinhamento de plantio em um 
espaçamento de $50 \times 50 \mathrm{~cm}$. O tratamento dos solos com o composto e adubo consistiu no revolvimento da terra e adição de cerca de 30 gramas de composto por cada pé de couve, utilizando enxadas. Em relação ao adubo NPK, foram adicionados manualmente $30 \mathrm{~g} / \mathrm{m}^{2}$. Durante o período de crescimento, foram realizadas mais duas adubações nas parcelas de ensaio. A segunda aplicação ocorreu no $15^{\circ}$ dia e a terceira no $30^{\circ}$ dia.

\begin{tabular}{|l|l|l|}
\hline P1 & P2 & P3 \\
\hline P2 & P3 & P1 \\
\hline P3 & P1 & P2 \\
\hline
\end{tabular}

P1: Parcela de controle

P2: Parcela tratada com composto

P3: Parcela tratada com adubo

Figura 3: Esquema de distribuição das parcelas.

Os tratamentos foram: controle sem adubação, com adubação mineral e com biossólido. As doses de biossólido em base seca foram determinadas em função do teor de nitrogênio total, fósforo e potássio que corresponderam à relação 0,5 : 1,0: 0,2 (NPK do biossólido).

Assim, foram definidos quatro parâmetros para estudo da produtividade relativa da cultura: altura da planta, comprimento, largura e peso da folha. Foi definido um número médio de sete folhas para os ensaios. Essas folhas eram escolhidas tendo em conta "perfeição" aparente.

Ao final de 90 dias após o plantio das mudas no campo definitivo, foi feita a primeira colheita, com o propósito de determinar o comprimento, a largura e o peso da folha. $O$ parâmetro altura da planta foi medido no campo. A análise da produtividade relativa foi calculada como percentual da produtividade alcançada com adubação pelo biossólido. Os dados obtidos foram submetidos à análise de variância teste de médias, sendo efetuada a regressão linear simples para doses de biossólido.

\section{Resultados e discussões}

\subsection{Produção do composto}

O composto foi produzido e submetido a testes que permitiram definir o grau de maturação do mesmo e sua composição, apresentada na Tabela 2.

O biossólido, como derivado de lodo de esgoto de um processo aeróbio, apresentou um $\mathrm{pH}$ recomendável para uso agrícola, não influenciando a disposição dos demais nutrientes no solo [15]. O biossólido se comporta como um condicionante de solo devido ao alto teor de matéria orgânica e como fonte de vários outros nutrientes de interesse para a nutrição de plantas. Nota-se também que não há riscos de insolubilização do alumínio, nem diminuição do efeito retrogradante para a planta, pois o $\mathrm{pH}$ dos biossólidos encontra-se na faixa recomendável e permite a troca deste íon do solo para a planta.

A quantidade de matéria orgânica no biossólido (Tabela 2) é elevada. A concentração média de matéria orgânica em biossólidos deve ser superior a $25 \mathrm{~g} / \mathrm{dm}^{3}$ [16]. Este é um parâmetro importante no solo, principalmente do ponto de vista qualitativo, pois permite prever características que auxiliam no manejo físico e químico dele. Os nutrientes presentes nos biossólidos são consequência da degradação da matéria orgânica, rica em nitrogênio, fósforo e demais micronutrientes. Assim, a maior ou menor disponibilidades desses está relacionada com o tipo de lodo usado como matéria prima para a produção dos biossólidos e com $\mathrm{pH}$ do meio em que se degradam as macromoléculas, pois em valores de $\mathrm{pH}$ baixos ou altos, ocorre a redução ou inibição da atividade microbiana sobre os substratos orgânicos.

Por sua vez, a quantidade de fósforo presente no biossólido (Tabela 2) permite, tendo em conta o pH, uma boa resposta a adubação fosfatada por parte das plantas, a despeito das pequenas quantidades absorvidas por elas, pois o fósforo constitui um macronutriente primário [17 e 18]. O nitrogênio nos biossólidos está disponível na forma orgânica e inorgânica, mas nem todo nitrogênio é disponível como nutrientes para as plantas, pois o ele apresenta um acentuado e complexo dinamismo no sistema solo-planta, caracterizado por sua alta mobilidade e diversas reações de transformação da porção orgânica, mediadas por micro-organismos, ocasionando a presença da forma nítrica e mineral, que é facilmente absorvida pelas plantas [1].

A soma de bases trocáveis, observada na Tab. 2, é um atributo que reflete a soma de cálcio, magnésio e potássio, podendo incluir o sódio, todos na forma trocáveis do complexo de troca de cátions do solo. Os valores absolutos desses componentes refletem os seus níveis de forma individual. A soma de bases indica o número de cargas negativas dos coloides ocupados pelas bases [19].

A quantidade de sódio presente no biossólido (Tabela 2) não tem influência nutricional sobre as plantas, tal como o cálcio ou o magnésio, e o nível mínimo desses elementos deve ser 2,0 $\mathrm{mmol}_{\mathrm{c}} / \mathrm{dm}^{3}$ [20], sendo que o presente biossólido apresenta um nível médio de 2,2 $\mathrm{mmol}_{\mathrm{c}} / \mathrm{dm}^{3}$ desses micronutrientes.

O biossólido apresenta interessantes propriedades agronômicas para suprir de nutrientes um solo agrícola. Mesmo tendo uma boa composição nutricional para as plantas, ele não pode ser visto como um substituto do adubo mineral, mas sim como um condicionador do solo, cujo uso permite melhorar suas condições gerais em longo prazo, fazendo as plantas aproveitarem melhor o adubo nele incorporado [15].

Tabela 2: Resultados da análise laboratorial do composto (biossólido). CTC - capacidade de troca catiônica, CE - condutividade elétrica, MO - matéria orgânica, $\mathrm{N}_{\text {total }}$ - Nitrogênio total

\begin{tabular}{|c|c|c|c|c|c|c|c|c|c|c|}
\hline Parâm. & $\begin{array}{c}\text { Bases trocáveis } \\
\left(\mathbf{m m o l}_{\mathrm{c}} / \mathbf{d m}^{3}\right)\end{array}$ & $\begin{array}{c}\mathrm{Al}^{3+} / \mathrm{CTC} \text { efetiva } \\
\left(\mathbf{m m o l}_{\mathrm{c}} / \mathbf{d m}^{3}\right)\end{array}$ & $\begin{array}{c}\mathrm{Na}^{+} / \mathrm{CTC} \text { efetiva } \\
\left(\mathrm{mmol}_{\mathrm{c}} / \mathbf{d m}^{3}\right)\end{array}$ & $\begin{array}{c}\mathrm{Ca}^{+} / \mathbf{M g}^{2+} \\
\left(\mathbf{m m o l}_{\mathrm{c}} / \mathbf{d m}^{3}\right)\end{array}$ & $\begin{array}{c}\mathbf{M g}^{2+1} \mathbf{K}^{+} \\
\left(\mathbf{m m o l}_{\mathbf{c}} / \mathbf{d m}^{3}\right)\end{array}$ & $\begin{array}{c}\mathbf{C E} \\
\left(\mathbf{S} . \mathbf{m} / \mathbf{m m}^{2)}\right.\end{array}$ & $\mathbf{p H}$ & $\begin{array}{l}\text { P-Olsen } \\
\left(\mathbf{m g} / \mathbf{d m}^{3}\right)\end{array}$ & $\underset{\left(\mathrm{g} / \mathrm{dm}^{3}\right)}{\mathbf{M O}}$ & $\begin{array}{c}\mathbf{N}_{\text {total }} \\
\left(\mathbf{m g} / \mathbf{d m}^{3}\right)\end{array}$ \\
\hline Valor & 22,25 & 0,00 & 6,89 & 2,22 & 0,38 & 1,25 & 6,24 & 16,26 & 59,34 & 8,78 \\
\hline
\end{tabular}




\subsection{Resultados do ensaio de campo}

Os resultados dos ensaios de campo, apresentados na Tabela 3, foram obtidos através da medição da altura das plantas, do comprimento, largura e do peso das folhas, tendo em conta a primeira e segunda colheita, com aplicações de biossólidos em cada um dos ensaios.

Os ensaios referentes à altura das plantas (Tabela $4 \mathrm{e}$ Figura 4) mostram que a couve tratada com biossólido apresenta uma altura média relativamente maior, $27,36 \mathrm{~cm}$, que a da couve não tratada (testemunha), com altura média de $18,36 \mathrm{~cm}$, e uma altura relativamente menor em relação à couve tratada com o adubo mineral, $35,93 \mathrm{~cm}$. A diferença significativa se deve ao fato do biossólido não apresentar proporcionalmente os macronutrientes encontrados no adubo mineral, pois nem sempre os macronutrientes que poderão existir nos biossólidos estarão disponíveis de forma equilibrada e de modo que as plantas possam utilizá-lo no curto prazo de tempo [21].

Em relação à largura da folha, notou-se (Tabela 4 e Figura 4) que as amostras de testemunha apresentaram uma largura média de $12,86 \mathrm{~cm}$, significativamente inferior a couve tratada com biossólido, que apresentou uma largura média de 16,86 cm.

A couve tratada com adubo mineral apresentou uma largura média maior, $20,95 \mathrm{~cm}$. A melhoria foliar é consequência da disponibilidade de nutrientes no solo, especialmente dos macronutrientes [22].

São justificáveis as diferenças significativas encontradas no ensaio em relação à variável comprimento da folha [21]: a couve tratada com adubo mineral apresentou um comprimento médio relativamente maior, $28,18 \mathrm{~cm}$, seguida da tratada com biossólido, com comprimento médio de $20,13 \mathrm{~cm}$, e a couve não tratada, que apresentou $17,76 \mathrm{~cm}$.

É justificável a necessidade da presença de grandes quantidades de macronutrientes, como $\mathrm{N}, \mathrm{P}, \mathrm{K}, \mathrm{Ca}, \mathrm{S}$ e $\mathrm{Mg}$, e em menores quantias de micronutrientes, $\mathrm{Mn}, \mathrm{Zn}, \mathrm{Cu}, \mathrm{Fe}, \mathrm{B}$ e $\mathrm{Cl}$, por exemplo, como fator determinante no crescimento das hortaliças [23]. Esse aspecto justifica os resultados dos ensaios referentes ao peso das folhas, tendo-se notado que as folhas da couve tratada com adubo mineral mostraram um peso médio de
908,00 g, enquanto que a folha tratada com o biossólido teve um peso médio de $513,25 \mathrm{~g}$ e a testemunha apresentou um peso médio de $42,65 \mathrm{~g}$.

As diferenças significativas nos parâmetros estudados são justificadas pela desproporcionalidade da composição do biossólido quando comparado com o adubo mineral. Isso porque a relação desbalanceada dos nutrientes nos biossólidos persiste em razão da sua mineralização [21]. O potássio, que é um macronutriente altamente solúvel em água, escapa facilmente dos biossólidos.

Tabela 4: Resultados médios dos ensaios P1 - campo não tratado (testemunho), P2 - campo tratado com biosólido (composto), P3 - campo tratado com NPK.

\begin{tabular}{|c|c|c|c|c|}
\hline \multirow{5}{*}{ 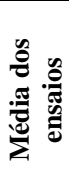 } & \multirow[t]{2}{*}{ Parâmetro } & \multicolumn{3}{|c|}{ Média dos Ensaios } \\
\hline & & P 1 & P 2 & P 3 \\
\hline & Altura das plantas $(\mathrm{cm})$ & 18,36 & 27,36 & 35,93 \\
\hline & Comprimento das folhas $(\mathrm{cm})$ & 17,76 & 20,13 & 28,18 \\
\hline & Largura das folhas $(\mathrm{cm})$ & 12,86 & 16,86 & 20,95 \\
\hline & Peso das folhas (g) & 42,65 & 513,25 & 908,00 \\
\hline
\end{tabular}

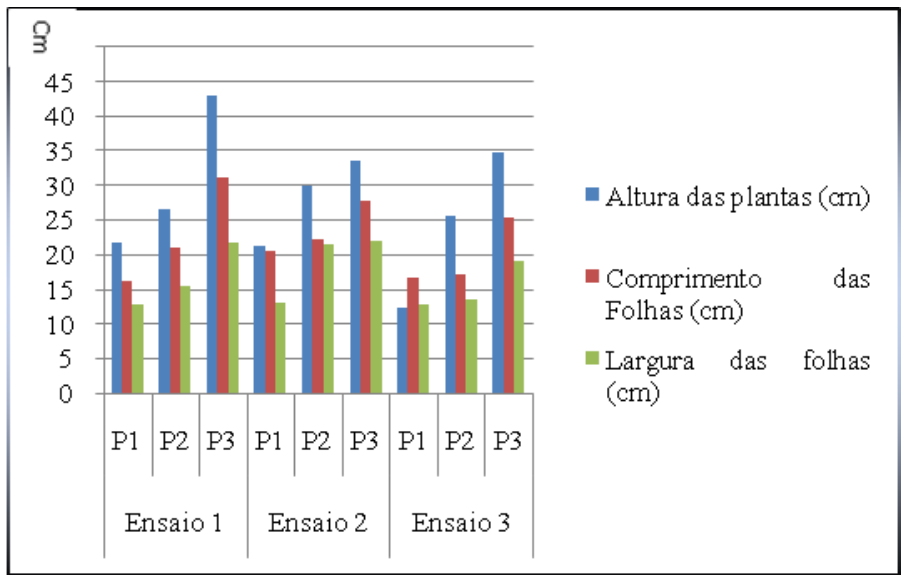

Figura 4: Efeito do uso de biossólidos sobre a dinâmica do crescimento da couve

A Figura 4 traduz a influência da disponibilidade de nutrientes no solo no desenvolvimento da planta. Os biossólidos

Tabela 3: Resultados dos ensaios de campo. $\mathrm{P}_{1}$ : campo não tratado (testemunho); $\mathrm{P}_{2}$ : campo tratado com biossólido (composto); $\mathrm{P}_{3}$ : campo tratado com NPK. Parâmetro Ensaio 1 Ensaio 2 Ensaio 3

\begin{tabular}{|c|c|c|c|c|c|c|c|c|c|c|}
\hline \multirow[t]{5}{*}{ Primeira } & & $\mathrm{P}_{1}$ & $\mathrm{P}_{2}$ & $\mathrm{P}_{3}$ & $\mathrm{P}_{1}$ & $\mathrm{P}_{2}$ & $\mathrm{P}_{3}$ & $\mathrm{P}_{1}$ & $\mathrm{P}_{2}$ & $\mathrm{P}_{3}$ \\
\hline & Altura das plantas $(\mathrm{cm})$ & 23,4 & 31,2 & 46,0 & 22,2 & 30,0 & 36,0 & 14,2 & 30,0 & 39,6 \\
\hline & Comprimento das folhas $(\mathrm{cm})$ & 21,2 & 21,7 & 32,5 & 21,2 & 24,2 & 32,7 & 13,2 & 14,0 & 20,0 \\
\hline & Largura das folhas $(\mathrm{cm})$ & 15,5 & 20,0 & 23,2 & 15,5 & 23,2 & 23,2 & 13,2 & 14,0 & 20,0 \\
\hline & Peso das folhas (g) & 60,0 & 250,0 & 1298,0 & 50,9 & 869,5 & 1220,0 & 47,0 & 610,0 & 720,0 \\
\hline \multirow[t]{4}{*}{ Segunda } & Altura das plantas $(\mathrm{cm})$ & 20,0 & 22,0 & 40,0 & 20,1 & 30,0 & 31,2 & 10,3 & 21,0 & 30,0 \\
\hline & Comprimento das folhas $(\mathrm{cm})$ & 11,0 & 20,2 & 30,0 & 20,0 & 20,3 & 23,0 & 20,0 & 20,4 & 30,9 \\
\hline & Largura das folhas $(\mathrm{cm})$ & 10,0 & 10,9 & 20,3 & 10,8 & 20,0 & 21,0 & 12,2 & 13,1 & 18,0 \\
\hline & Peso das folhas (g) & 40,0 & 150,0 & 900,0 & 30,0 & 740,0 & 800,0 & 28,0 & 460,0 & 510,0 \\
\hline \multirow{4}{*}{$\begin{array}{l}\text { Média } \\
\text { dos } \\
\text { ensaios }\end{array}$} & Altura das plantas $(\mathrm{cm})$ & 21,70 & 26,60 & 43,00 & 21,15 & 30,00 & 33,60 & 12,25 & 25,50 & 34,80 \\
\hline & Comprimento das folhas $(\mathrm{cm})$ & 16,10 & 20,95 & 31,25 & 20,60 & 22,25 & 27,85 & 16,60 & 17,20 & 25,45 \\
\hline & Largura das folhas $(\mathrm{cm})$ & 12,75 & 15,45 & 21,75 & 13,15 & 21,60 & 22,10 & 12,70 & 13,55 & 19,00 \\
\hline & Peso das folhas $(\mathrm{g})$ & 50,00 & 200,00 & 1099,00 & 40,45 & 804,75 & 1010,00 & 37,50 & 535,00 & 615,00 \\
\hline
\end{tabular}


apresentam grande potencial de uso como fertilizantes e condicionadores do solo e, quando atendem aos requisitos necessários, quanto à concentração de metais pesados e patógenos, podem substituir parcial ou totalmente os fertilizantes minerais [24]. Nesse sentido, os biossólidos obtidos à base lodo de ETE industrial, solo e palha de soja apresentam quantidades ínfimas de potássio, isso os torna desprovido de um dos macronutrientes importantes para o desenvolvimento da planta, fator que pode ter influenciado na diferença significativa dos valores médios obtidos em relação aos parâmetros de análise.

A diferença significativa dos resultados médios obtidos (Tabela 4) é conseqüência da dosagem equivalente de proporções aplicadas de biossólido e adubo mineral, que foi respectivamente de $30 \mathrm{~g}$ por pé de couve e $30 \mathrm{~g}$ por metro quadrado. No entanto [25], devido ao alto teor de umidade, são necessárias aplicações de grandes quantidades de biossólidos para atingir a equivalência nutricional dos fertilizantes minerais. $\mathrm{O}$ adubo mineral apresenta uma proporção média de nutrientes (NPK) de 1:2:1 [22], enquanto que os biossólidos apresentaram uma proporção média de 0,5:2,0:0,2, notando-se claramente a baixa disponibilidade de nitrogênio e potássio nesse biossólido. Mesmo assim, esse biossólido teve influência positiva no crescimento da couve se comparada com a couve da parcela de controle.

A produtividade do solo aumentou $40,3 \%$ pela aplicação dos biossólidos. Esse valor corresponde à metade do efeito da produtividade em relação às parcelas tratadas com adubo mineral, cuja diferença em relação às parcelas tratadas com biossólidos é de 48,7\%.

\section{Conclusões}

O composto produzido à base de lodo de ETE, palha de soja e terra pode ser considerado um biossólido, pois apresenta o conjunto de nutrientes necessários para melhorar a fertilidade do solo, o estado nutricional e produtividade da planta.

A aplicação dos biossólidos na cultura da couve é economicamente viável em relação ao adubo mineral. Para este estudo os biossólidos incrementaram em $50 \%$ a produtividade do solo quando comparado ao adubo mineral. Este biossólido pode ser recomendado para melhorar o cultivo da couve, pois ele influencia positivamente no crescimento da planta.

A reciclagem do lodo de ETE é, portanto, uma alternativa viável de disposição desse lodo, pois os agricultores poderão reduzir os custos de produção e manter a produtividade. No entanto, é necessária a elaboração de planos técnicos de aplicação que obedeçam à legislação e garantam a aplicação segura do resíduo.

Há necessidade de se efetuar estudos relacionados à dosagem específica e uniforme do biossólidos em diferentes tipos de solos, bem como a suplementação com fontes alternativas de potássio, nitrogênio e outros micronutrientes necessários.

\section{Agradecimentos}

Os autores agradecem ao Instituto de Investigação Agronômica de Moçambique da Região Norte pela disponibilidade de veículos e técnicos para a realização da pesquisa de campo em Moçambique, ao CNPq pela bolsa de doutorado concedida, e à Fundação Calouste Gulbenkian pelo apoio financeiro à pesquisa.

\section{AGRONOMIC EVALUATION OF A BIOSOLID IN THE PRODUCTIVITY OF CABBAGE}

\section{ABSTRACT}

The present work assesses the agronomic feasibility of a biosolids resulting from the sludge mixture of ETE's soft drink industry, soybean's straw and soil for growing cabbage Brassica oleleracea of tronchuda variety. The field trial was conducted in a characteristically pedalferic soil, especially the clay-red sandy soil, differentiated on the basis of average or clayey, brownreddish surface layer in the period from February to June 2012. The produced biosolids presented a nutritional ratio of 0.5 : 1.0: 0.2 . The test field was divided into 9 portions, in which 3 of them were treated with biosolids, 3 with mineral fertilizer and the remaining 3 were defined as control plots. In each plot treated with sewage sludge were added 30 grams of this by cabbage standing. The relative productivity was defined taking into account the parameters: plant height, leaf length, leaf width and weight of the sheet. The biosolids improved soil fertility, the nutritional status and the productivity of cabbage, surpassing the portion control at about $40.3 \%$, but had a relatively lower efficiency that the share of mineral fertilizer in the order of $48.7 \%$, it can be considered that the biosolids had a closer performance to that of mineral fertilizer output. The results show that the sewage sludge produced in sewage sludge treatment base station of the soft drink industry increases the productivity of the soil.

Keywords: WWTP sludge, sewage sludge, soil fertility, cabbage Brassica oleleracea.

\section{Referências}

[1] ANDREOLI, C. V., et al. Resíduos Sólidos do Saneamento: Processamento, Reciclagem e Disposição Final. Curitiba: PROSAB, 2001.

[2] EUROPEAN COMISSION. Disposal and recycling routes for sewage sludgePart 1 Sludge use acceptance report. Luxemburg. Office for Official Publications of the European Communities, 2001.

[3] CLAPP, C. E. Sewage Sludge Organic Matter and Soil Properties. In: CHEN, Y: AVNIMELECH, Y. The Role of Organic Matter in Modern Agriculture. Netherland, Martinus Nijhoff, 1994. 
[4] SMITH, S. R. Are Controls or Organics Contaminants Necessary to Protect the Environment When Sewage Sludge is used in Agriculture? Progress in Environmental Science 1, 1996

[5] SOCCOL, V. T.; PAULINO, R.C.; CASTRO E.A.. Agentes patogênicos: Helmintos e protozoários. In: ANDREOLI, C.V.; FERNANDES, F.; LARA, I.A. (Org). Reciclagem de biossólidos: Transformando problemas em soluções. Curitiba: SANEPAR/FINEP, 1999

[6] CANELLAS, L. P., et al. Avaliação de Características de Ácidos Húmicos de Resíduos de Origem Urbana: I - Métodos espectroscópios (UV-vis, IV, RMN, CCP/MAS) e microscopia eletrônica de varredura. Revista brasileira de ciências do solo. Viçosa, 2000.

[7] MORETTI, S. M. L. Uso de Lodo de Esgoto e Composto de Lodo com Poda de Árvore na Cultura da Cana-de-açúcar. Piracicaba, 2013.

[8] BOVI, M. L. A. et al. Lodo de Esgoto e Produção de Palmito em Pumpunheira. Revista brasileira de ciências do solo. Viçosa, 2007.

[9] MELO, W. J., et al. Nickel in a Tropical Soil Treated with Sewage Sludge and Cropped with Maize in a Long-term Field Study. Soil biology and biochemistry. Oxford, 2007

[10] FRANCO, A. Aplicação do Lodo de Esgoto em Cana Planta como Fonte de Nitrogênio e Fósforo e seu Impacto Ambiental. Piracicaba, 2009.

[11] INAM, Instituto Nacional de Meteorologia de Moçambique. Maputo, 2012.

[12] INIA, Instituto Nacional de Investigação Agronómica. Manual de Identificação e Quantificação de Solos e Águas em Moçambique. Maputo, 1995.

[13] CUNLIFFE, G. Support to Niassa (Mozambique) Provincial processes to develop community- focused Natural resource management: Forest resources, fisheries and wildlife". South Africa, 2006.

[14] EATON, A. D. et al.,. Standard Methods for Examination of Water and Wastewater. $19^{\text {th }}$ ed. American Public Health Association, Washington, DC, 1995

[15] FERNANDES, F. \& DA SILVA, S. M.. Manual Prático para Compostagem de Biossólidos. PROSAB, Londrina, 1997.

[16] TOMÉ Jr., J.B.. Manual para interpretação de análise de solo. Guaíba: Livraria e Editora Agropecuária, 1997.

[17] NOVAIS, R. F. \& SMITH, T. J. Fósforo em Solos e Planta em Condições Tropicais. $1^{a}$ Edição UFV, Viçosa - MG, 1999.

[18] DA SILVA, L. C. Níveis e Fontes de Fósforo Adicionados a um Biossólido Tratado pelo Processo N-Viro Aplicado em Solos Ácidos do Paraná. UFP, Curitiba, 2007.

[19] LOPES, A. S. \& GUILHERME, L. R. Interpretação de análise de solos: Conceitos e Aplicações. Boletim Técnico nr. 2. ANDA. Lavras, 2004.

[20] CARVALHO, M.B. \& VIEIRA, G.E.G. Características e Utilização de Adsorvente Carbonoso obtido em Processo de Pirólise a partir de lodo de ETE, Palmas-2011.

[21] BETTIOL, W \& CAMARGO, O. Lodos de esgotos: Impactos Ambientais na Agricultura. Embrapa Meio Ambiente. São Paulo, 2006.

[22] MALAVOLTA, E. et al. Avaliação do estado nutricional das plantas: princípios e aplicações. 2ed. Piracicaba, Potofos, 1997.

[23] AMARO, G. B. et al. Recomendações Técnicas para o cultivo de hortaliças e agricultura familiar. Brasília, Embrapa (Circular técnica, 47) 2007.
[24] TRANNIN, I. C. B.; SIQUEIRA, J. O. \& MOREIRA, F. M. Avaliação Agronômica de um Biossólido Industrial para a Cultura do Milho. Pesq. Agropec. Bras., nr. 40, 2005.

[25] RAIJ, B. Van. Uso Agrícola de Biossólidos. Seminários sobre Gerenciamento de Biossólidos no Mercosul, Curitiba: Sanepar, ABES, 1998. 